\title{
Information content of stream level class data for hydrological model calibration
}

\author{
H. J. Ilja van Meerveld ${ }^{1}$, Marc J. P. Vis ${ }^{1}$, and Jan Seibert ${ }^{1,2}$ \\ ${ }^{1}$ Department of Geography, University of Zurich, Zurich, Switzerland \\ ${ }^{2}$ Department of Earth Sciences, Uppsala University, Uppsala, Sweden \\ Correspondence to: H. J. Ilja van Meerveld (ilja.vanmeerveld@geo.uzh.ch)
}

Received: 8 February 2017 - Discussion started: 14 February 2017

Revised: 14 July 2017 - Accepted: 18 August 2017 - Published: 28 September 2017

\begin{abstract}
Citizen science can provide spatially distributed data over large areas, including hydrological data. Stream levels are easier to measure than streamflow and are likely also observed more easily by citizen scientists than streamflow. However, the challenge with crowd based stream level data is that observations are taken at irregular time intervals and with a limited vertical resolution. The latter is especially the case at sites where no staff gauge is available and relative stream levels are observed based on (in)visible features in the stream, such as rocks. In order to assess the potential value of crowd based stream level observations for model calibration, we pretended that stream level observations were available at a limited vertical resolution by transferring streamflow data to stream level classes. A bucket-type hydrological model was calibrated with these hypothetical stream level class data and subsequently evaluated on the observed streamflow records. Our results indicate that stream level data can result in good streamflow simulations, even with a reduced vertical resolution of the observations. Time series of only two stream level classes, e.g. above or below a rock in the stream, were already informative, especially when the class boundary was chosen towards the highest stream levels. There was some added value in using up to five stream level classes, but there was hardly any improvement in model performance when using more level classes. These results are encouraging for citizen science projects and provide a basis for designing observation systems that collect data that are as informative as possible for deriving model based streamflow time series for previously ungauged basins.
\end{abstract}

\section{Introduction}

Streamflow data are crucial for water resource management decisions and the calibration of hydrological models. However, streamflow data are only available for a number of sites and gauging stations are not always installed at representative locations. There is, for instance, a lack of streamflow gauges in small headwater streams (Kirchner, 2006) and in developing countries (Mulligan, 2013). Although technological developments provide the possibility to expand the measurement network, the reality is that, due to budget cuts, observation networks often shrink (Kundzewicz, 1997) rather than expand. Remote sensing images can be used to estimate stream levels or streamflow, particularly for wide lowland rivers (Smith, 1997; Milewski et al., 2009; Pavelsky, 2014; Van Dijk et al., 2016), but estimation of streamflow from satellite images is likely to remain problematic for small headwater streams.

Stream level data are easier to obtain than streamflow data because they do not require any information on the rating curve. Seibert and Vis (2016) tested whether stream level data can be used to constrain a simple hydrological model. The results for $\sim 600$ catchments in the USA showed that stream level data can be surprisingly informative for hydrological model calibration. This applies especially for humid and wet catchments (defined as catchments where the annual precipitation is larger than the annual potential evapotranspiration), for which the median efficiency (Nash and Sutcliffe, 1970) of models calibrated with stream level data was generally only $0.10-0.15$ units below that of models calibrated with streamflow data; for all but one catchment the difference was less than 0.17 . For dry catchments, additional informa- 
tion on the volume of streamflow, such as the annual mean flow or streamflow percentiles, was needed.

Even though the price of water level recorders has significantly gone down in recent years and their datalogging capacity has increased, it is not feasible to install a water level recorder in every ungauged catchment. It is, therefore, useful to also consider the use of other approaches to obtain water level data. Citizen science is now more frequently used to obtain environmental data over large areas (Savan et al., 2003; Bonney et al., 2009; Graham et al., 2011; Fohringer et al., 2015; Huddart et al., 2016; Wiseman and Bardsley, 2016). Little et al. (2016) gave citizen scientists water level sounders to measure groundwater levels in private wells and found that these measurements provided valuable data on groundwater levels across a large area in Alberta, Canada, and that the measurements were relatively accurate; the root mean square error between citizen scientist observed water levels and pressure transducer based water levels ranged between 3 and $11 \mathrm{~cm}$. Lowry and Fienen (2013) installed staff gauges in rivers and asked citizen scientists to send stream level measurements via text messages. They showed that the accuracy of the crowd-sourced measurements and pressure transducer data were similar to the staff gauge gradations (root mean square error of $0.5 \mathrm{~cm}$ ). However, it is not feasible to install a staff gauge in every ungauged catchment or to equip all citizen scientists with water level recorders. Therefore, it is useful to also design citizen science approaches that do not require staff gauges or water level sensors. Citizen scientists have for example successfully mapped the occurrence of streamflow in intermittent streams (Turner and Richter, 2011) and water levels are a standard measurement in the Earthwatch FreshWater Watch program (https://freshwaterwatch.thewaterhub.org/). Estimates of relative stream levels or stream level classes based on features in the stream or on the streambank (i.e. whether the water level is above or below a certain rock) are easier and can be done more quickly than actual water level measurements and are, therefore, likely suitable for citizen science projects where no staff gauges are available. However, the (vertical) resolution of these data is less than those of actual stream level measurements.

Information from time lapse cameras or webcams can also be used to obtain information on stream water level classes. Pixel classification or image recognition to determine whether the water level is above or below a certain point can be used to determine the relative stream water level, even if no other information about the stream or the cross section is available. Several studies have shown that cameras can be used for accurate streamflow estimation (Muste et al., 2011; Tsubaki et al., 2011; Hilgersom and Luxemburg, 2012; Royem et al., 2012; Stumpf et al., 2016), but these studies used dedicated cameras that focused directly on the stream and often required information about the stream channel cross section. While promising, it is unlikely that many of the ungauged streams will be equipped with these systems.
However, streams are often included in the pictures of existing webcams or time lapse cameras that were installed for other reasons, e.g. to show the snow conditions on a ski slope or to highlight the view from a hotel. The information from these webcams can be used to obtain information about the relative changes in the stream level or width, but this information might not be very precise because of the sub-optimal angle of the camera. It is, thus, more likely that these images can be used to obtain information about the relative stream level or stream width (class), rather than the actual water level. Remotely sensed data can also be used to rank stream levels or stream width. These data, however, as promising as they are, have limitations regarding their accuracy and resolution (and will likely have them for the foreseeable future). Thus, also for these measurements time series of level (or width) classes are more realistic than high-resolution time series of actual water levels.

For crowd based (or citizen science) observations, but also for data from webcams or satellites, the resolution of the stream level data will be significantly poorer than for data obtained by a dedicated water level sensor. To determine the effect of this loss of information, we tested the usefulness of these new types of stream level class data for constraining a simple bucket-type hydrological model. The aim was to provide a basis for designing citizen science projects that collect data that are as informative as possible and that can be used to derive model based streamflow time series. We pretended that stream level class observations were available continuously (daily), but only at a limited vertical resolution by transferring the streamflow data to stream level classes. We then tested how the number of stream level classes (i.e. the resolution) influenced the information content of the data with regard to constraining the model. Furthermore, we studied the effect of different locations of the class boundaries on model performance.

\section{Methods}

\subsection{Study catchments and dataset}

This study largely followed the methodology of Seibert and Vis (2016), who evaluated the value of water level time series for model calibration for almost 600 catchments in the contiguous US based on continuous, high-resolution stream level data. In this study, the model was calibrated based on stream level class data for a subset of these catchments. The 100 catchments used in this study were chosen randomly from the catchments used by Seibert and Vis (2016) and are spread across the contiguous US. The hydrometric data for these 1 to $12584 \mathrm{~km}^{2}$ catchments were obtained from the dataset for 671 catchments of Newman et al. (2015). The precipitation $(P)$ was derived from DAYMET (Thornton et al., 2012). The mean annual precipitation varied for the different catchments between 249 and $3113 \mathrm{~mm} \mathrm{yr}^{-1}$. The 


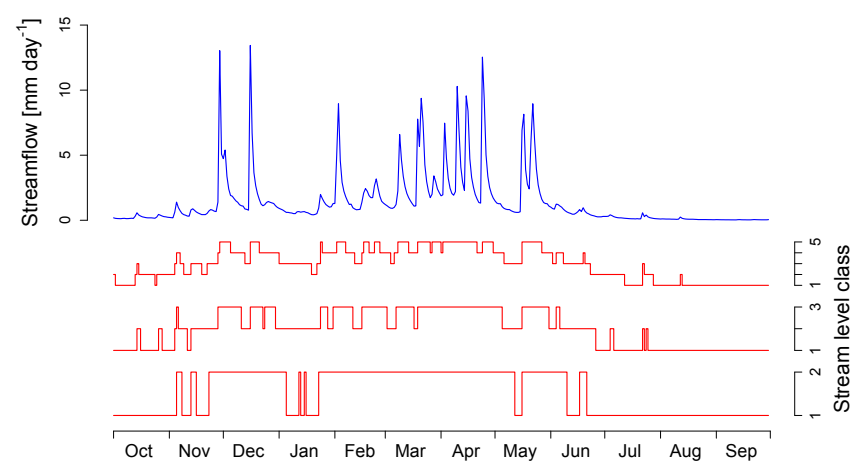

Figure 1. Time series of the observed streamflow (blue) for the first year of simulation (October 1982-September 1983) for catchment 002011460 (Back Creek near Sunrise, VA), a medium sized catchment $\left(235 \mathrm{~km}^{2}\right)$ with a medium aridity index (1.33), and the derived time series of the stream level class for the case of two, three and five level classes (red), where the stream level is in each water level class for, respectively, 50,33 and $20 \%$ of the time.

potential evapotranspiration $\left(E_{\mathrm{pot}}\right)$ was calculated with the Priestley-Taylor equation. The annual average runoff ratios calculated based on the precipitation at the mean elevation of the catchments varied between 0.05 and 1.18 (between 0.12 and 0.93 for $90 \%$ of the catchments). The aridity index $\left(P / E_{\mathrm{pot}}\right)$ varied between 0.25 and 4.33 . Of the 100 catchments, 22 are considered dry $\left(P / E_{\mathrm{pot}} \leq 1.0\right), 62$ are considered humid $\left(1.0<P / E_{\mathrm{pot}}<2.0\right)$ and 16 catchments are considered wet $\left(P / E_{\mathrm{pot}} \geq 2.0\right)$.

\subsection{Transformation of streamflow data into stream level classes}

In order to determine how many stream level classes are needed for model calibration, the daily average streamflow data were converted into time series of $n$ stream level classes, where $n$ varied from 2 to 20 (Fig. 1). In real citizen science projects the class boundaries are likely chosen based on features in the stream or on the stream bank (e.g. above or below a certain rock or marker), but in this study we chose the boundaries so that each class contained the same number of data points. This meant that for the simulations with two classes we converted all streamflow values above the median to water level class 2 and all streamflow values below the median to water level class 1 . Similarly, when using more classes we assigned the classes so that there were an equal number of measurements in each class (i.e. each class had observations for a fraction of $n^{-1}$ of the entire time period). For the cases with two and three stream level classes we also evaluated the optimal location of the class boundaries. For this, we systematically varied the class boundaries by changing the fraction of the time that the water level was in each class.

\subsection{Hydrological model}

The HBV (Hydrologiska Byråns Vattenbalansavdelning) model (Bergström, 1992; Lindström et al., 1997) was used in the HBV-light software implementation (Seibert and Vis, 2012). The HBV model is a frequently used bucket-type model and consists of different routines representing snow, soil, groundwater and stream routing processes. The HBV model, as it was applied here, has 14 free parameters, which are usually found by calibration or regionalization. Elevation bands of $200 \mathrm{~m}$ were used to represent catchment topography, whereas only one lumped land-cover class was used for each catchment. The parameter ranges for the 14 model parameters in the HBV model were similar to those used by Seibert and Vis (2016) and represent the range of typical parameter values found in previous studies worldwide.

\subsection{Model calibration and validation}

For each catchment the HBV model was calibrated for the period 1 October 1982-30 September 1996 using a genetic optimization algorithm (Seibert, 2000). The data from the 1 January 1980-30 September 1982 period were used for warming up the model. For model calibration, we maximized the Spearman rank correlation coefficient $\left(r_{\mathrm{s}}\right.$; Spearman, 1904) between the stream level class data and the simulated streamflow. The Spearman rank correlation evaluates the dynamics of the modelled streamflow and is highest $\left(r_{\mathrm{s}}=1\right)$ when stream level class and streamflow are strictly monotonically related. The advantage of using the Spearman rank correlation for model calibration based on stream level class data is that no information about the rating curve is needed. While the Spearman rank correlation does not evaluate streamflow volumes and, thus, a value of 1 does not ensure a perfect fit, the rank correlation can still be beneficial for model calibration, especially in humid catchments, where flow is constrained by the water balance (Seibert and Vis, 2016). Here we used the rank correlation to evaluate the dynamics of the "observed" stream level classes against the simulated streamflow time series. One could argue that the use of class data leads to a large number of ties (measurements with the same (mean) rank for the water level class), and $r_{\mathrm{s}}$ values of $1 \mathrm{can}$, due to these ties, thus, by definition of the Spearman rank correlation, not be obtained. However, since we are not interested in (or using) the absolute Spearman rank correlation values, and are only interested in the relative performance of different parameter sets, $r_{\mathrm{s}}$ can still be used for model calibration because its value is highest when the dynamics of the stream level classes and streamflow are most similar.

For each catchment, we used 100 independent model calibration trials, resulting in 100 parameter sets (one for each model calibration). For each of these (100) calibration trials, a total of 3500 model runs were done to find the optimum parameter set with the genetic algorithm. The 100 calibration parameter sets for each catchment were validated by compar- 


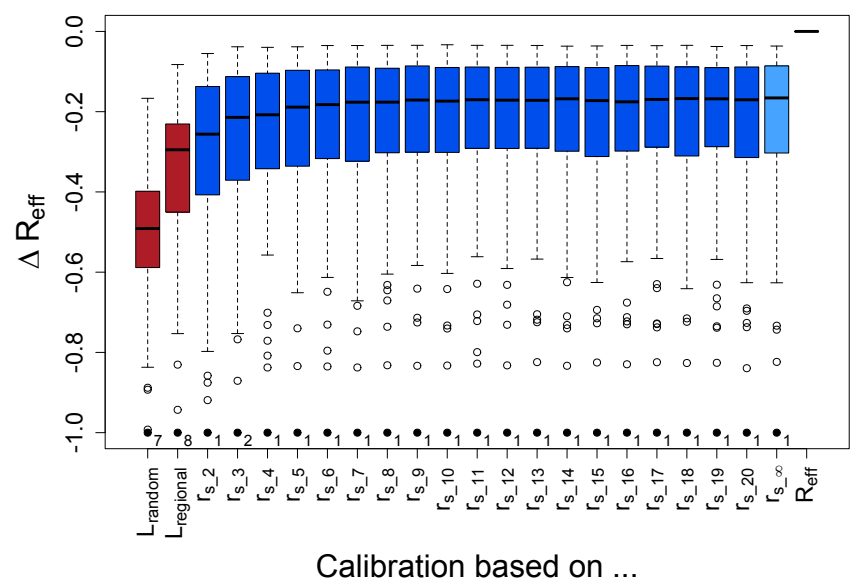

Figure 2. Box plots of the difference in the median model efficiency and the upper benchmark ( $\left.\Delta R_{\text {eff }}\right)$ for all 100 catchments for the models calibrated on stream level class data ( 2 to 20 classes; $r_{\mathrm{S} \_n}$ ), models calibrated on high-resolution stream level data $\left(r_{\mathrm{S} \_} \infty\right)$, and the two lower benchmarks ( $L_{\text {random }}$ and $\left.L_{\text {regional }}\right)$. The box represents the interquartile range, the solid line represents the median, the whiskers reach to the furthest catchment that is still within a distance of 1.5 times the interquartile range from the box, and the dots represent the outliers.

ing the simulated streamflow to the observed streamflow data using the model efficiency (Nash and Sutcliffe, 1970). For each catchment, the median value of the model efficiency for the 100 parameter sets was used to represent the performance of the model for that catchment.

\subsection{Benchmarks}

Different benchmarks were used to assess the performance of the models calibrated with the stream level class data: an upper benchmark that represents how good the model simulation would be if continuous streamflow data were available, and two lower benchmarks that represent a model simulation in the absence of any streamflow or stream level data.

For the upper benchmark $\left(R_{\text {eff }}\right)$, the model was calibrated for each catchment using the streamflow data and optimizing the model efficiency ( 100 calibration trials per catchment, each consisting of 3500 model runs). The median model efficiency of these 100 calibration trials was used as the upper benchmark value for each catchment. Because the goal of this study was to assess the value of stream level class data for model calibration, rather than to evaluate the ability of the model to simulate the streamflow, all model validation results for the stream level class data are given as the difference in model efficiency relative to this upper benchmark ( $\left.\Delta R_{\text {eff }}\right)$.

In addition, the simulations based on the stream level class data were compared to the simulations based on calibrations derived from high-resolution stream level data $\left(r_{\mathrm{s}_{-} \infty}\right)$. Here the model was calibrated by optimizing the Spearman rank correlation between the observed and modelled streamflow

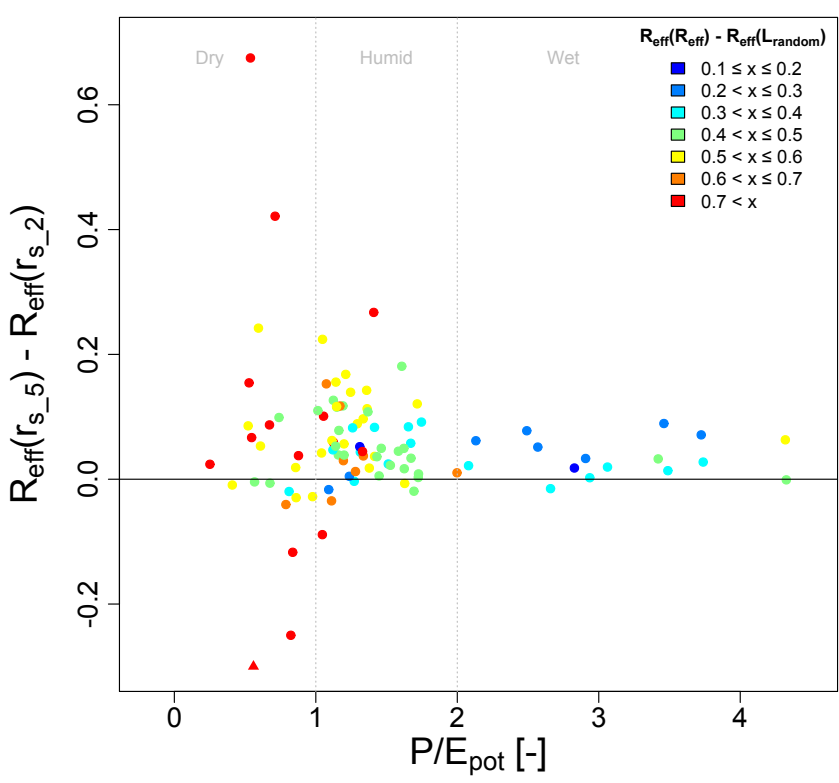

Figure 3. Difference in the median model validation result (model efficiency) for the models calibrated using two water level classes $\left(r_{\mathrm{s} \_2}\right)$ and five water level classes $\left(r_{\mathrm{s} \_5}\right)$ for all 100 catchments as a function of the aridity index $\left(P / E_{\text {pot }}\right)$. The colour of the symbols represents the difference between the upper and lower benchmarks (i.e. the difference in the median model performance when the model is calibrated with all available streamflow data $\left(R_{\text {eff }}\right)$ and when the model is run with randomly selected parameters (i.e. without any calibration; $\left.L_{\text {random }}\right)$ ). Triangles indicate outliers that would plot outside the range of the $y$ axis.

(cf. Seibert and Vis, 2016). These simulations represent a situation where a water level recorder is installed in the stream, and these data are used for model calibration.

For the first lower benchmark ( $L_{\text {random }}$ ), the model was run for each catchment 1000 times using randomly chosen parameters within the parameter ranges that were also used for model calibration. We used the median model performance for these 1000 parameter sets to represent the performance of the model with random parameters for that catchment. For the second lower benchmark ( $\left.L_{\text {regional }}\right)$, the model was run 9900 times using the 100 calibrated parameter sets for each of the 99 other catchments and the median model performance for these 9900 parameter sets was used to characterize the second lower benchmark for that catchment.

\section{Results}

\subsection{Model performance as a function of the number of water level classes}

Not surprisingly, the model efficiency was lower for the models calibrated with the stream level class data than for the models calibrated with the streamflow data (Fig. 2 and Table 1). However, the differences between the models cal- 
Table 1. Median, maximum and minimum model efficiencies for the 100 catchments for model calibrations using different types of data and the two lower benchmarks. Note that the difference in the median model efficiency for the model calibrations with all streamflow data $\left(R_{\text {eff }}\right)$ and the median model efficiency for the model calibrations with data for $n$ water level classes $\left(r_{\mathrm{S} \_} n\right)$ is not the same as the median of the differences in efficiency between the model calibrated with all streamflow data and the model calibrated with the stream level class data ( $\Delta R_{\mathrm{eff}}$ ) that is reported in the text and shown in the figures.

\begin{tabular}{|c|c|c|c|c|c|}
\hline Data used for model calibration & & $\begin{array}{r}\text { All catchments } \\
\qquad(n=100)\end{array}$ & $\begin{array}{r}\text { Dry catchments } \\
\qquad(n=22)\end{array}$ & $\begin{array}{r}\text { Humid catchments } \\
\qquad(n=62)\end{array}$ & $\begin{array}{r}\text { Wet catchments } \\
\qquad(n=16)\end{array}$ \\
\hline \multirow[t]{3}{*}{ Streamflow data (upper benchmark, $R_{\text {eff }}$ ) } & Median & $0.77^{*}$ & 0.77 & 0.75 & 0.86 \\
\hline & $\operatorname{Max}$ & 0.92 & 0.92 & 0.90 & 0.92 \\
\hline & Min & 0.53 & 0.56 & 0.53 & 0.64 \\
\hline \multirow[t]{3}{*}{ Water level data $\left(r_{\mathrm{S} \_} \infty\right)$} & Median & 0.58 & 0.32 & 0.58 & 0.80 \\
\hline & $\operatorname{Max}$ & 0.89 & 0.61 & 0.79 & 0.89 \\
\hline & Min & -1.48 & -1.48 & 0.13 & 0.53 \\
\hline \multirow[t]{3}{*}{5 stream level classes $\left(r_{\mathrm{s} \_5}\right)$} & Median & 0.56 & 0.29 & 0.57 & 0.79 \\
\hline & $\operatorname{Max}$ & 0.88 & 0.62 & 0.79 & 0.88 \\
\hline & Min & -1.68 & -1.68 & 0.10 & 0.53 \\
\hline \multirow[t]{3}{*}{3 stream level classes $\left(r_{\mathrm{s} \_3}\right)$} & Median & 0.54 & 0.27 & 0.55 & 0.76 \\
\hline & $\operatorname{Max}$ & 0.88 & 0.57 & 0.79 & 0.88 \\
\hline & Min & -1.71 & -1.71 & -0.14 & 0.52 \\
\hline \multirow[t]{3}{*}{2 stream level classes $\left(r_{\mathrm{s} \_2}\right)$} & Median & 0.49 & 0.28 & 0.49 & 0.72 \\
\hline & $\operatorname{Max}$ & 0.87 & 0.65 & 0.77 & 0.87 \\
\hline & Min & -0.57 & -0.57 & -0.12 & 0.47 \\
\hline \multirow[t]{3}{*}{ Parameters from other catchments ( $\left.L_{\text {regional }}\right)$} & Median & 0.43 & 0.21 & 0.43 & 0.70 \\
\hline & $\operatorname{Max}$ & 0.79 & 0.50 & 0.65 & 0.79 \\
\hline & Min & -5.56 & -5.56 & -2.54 & 0.43 \\
\hline \multirow[t]{3}{*}{ Random parameters ( $\left.L_{\text {random }}\right)$} & Median & 0.25 & 0.11 & 0.26 & 0.56 \\
\hline & $\operatorname{Max}$ & 0.76 & 0.38 & 0.66 & 0.76 \\
\hline & Min & -6.04 & -6.04 & -1.60 & 0.13 \\
\hline
\end{tabular}

* The median model efficiency for the $\sim 600$ catchments studied by Seibert and Vis (2016) was 0.74 .

ibrated with the high-resolution stream level data and the models calibrated with stream level class data were relatively small, as long as at least five stream level classes were used for model calibration (compare the results for $r_{\mathrm{S} \_5}$ and $r_{\mathrm{S} \_} \infty$ in Fig. 2 and Table 1). The median difference in efficiency for the models calibrated on high-resolution water level data and the models calibrated on five stream level classes was only 0.01 . The median difference was 0.06 when only two stream level classes were used. These differences are small compared to the 0.17 difference in median model efficiency for the models calibrated on continuous streamflow $\left(R_{\text {eff }}\right)$ and the high-resolution stream level data $\left(r_{\mathrm{s}_{-} \infty}\right)$.

A more detailed analysis of the increase in model performance with an increasing number of water level classes suggests that for the wet catchments model performance increased only slightly when increasing the number of water level classes from two to five, but that for some of the dry catchments model performance increased significantly when using more than two water level classes (Fig. 3). In general, the increase in model performance with an increasing number of stream level classes was largest for the catchments for which the difference in model performance between the upper and lower benchmarks was largest (Fig. 3).

\subsection{Comparison with the benchmarks}

Comparison of the performance of the models calibrated with stream level class data to the upper benchmark suggests that especially for the wet catchments the differences between traditional model calibration based on continuous streamflow data and the calibration based on the stream level class data were small (Fig. 4a and b). For the dry catchments, model calibration based on stream level class data led to larger errors in the simulated streamflow (Fig. 4a and b).

Comparison of the performance of the models calibrated with the stream level class data to the lower benchmarks suggests that the inclusion of stream level class data led to a huge improvement in model performance for some of the dry catchments (Fig. 4c and d). However, the differences in the median improvement in model efficiency when using the data for two stream level classes compared to the lower benchmark $\left(L_{\text {random }}\right)$ between the wet, humid and dry catchments were small $(0.23,0.23$ and 0.15 , respectively) and not statistically significant (Kruskal-Wallace test $p=0.09$ ). 

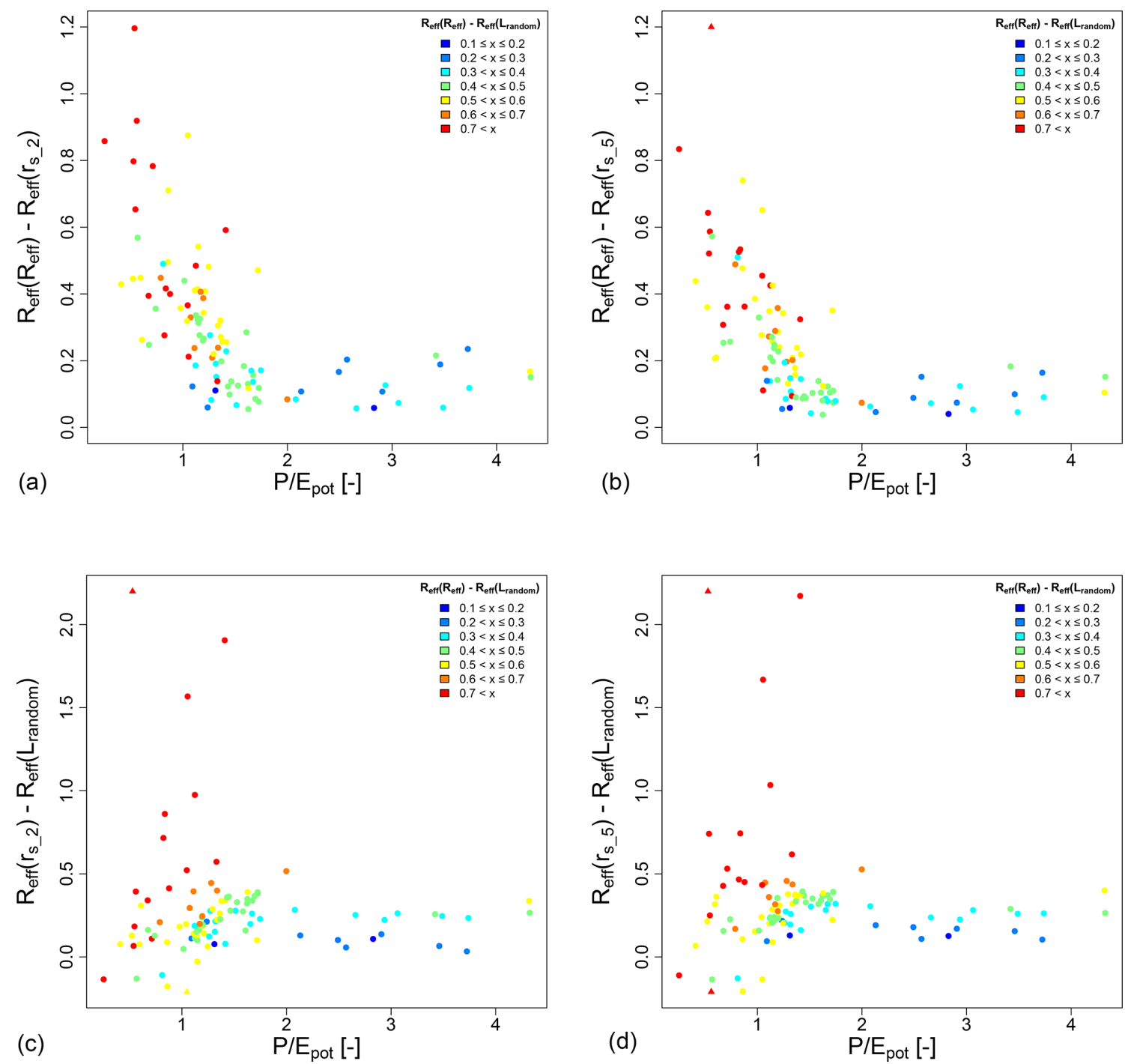

Figure 4. Difference in model validation results (model efficiency) for the models calibrated with data from two $\left(r_{\mathrm{S} \_2}\right.$; left) and five $\left(r_{\mathrm{S} \_5}\right.$; right) stream level classes and the upper benchmark $\left(R_{\text {eff }}\right.$; upper row) and the lower benchmark ( $L_{\text {random }}$; bottom row) as a function of the aridity index $\left(P / E_{\text {pot }}\right)$. Each dot represents one catchment; the colour of the symbol represents the difference in model efficiency between the upper and lower benchmarks for that catchment. Note the difference in the scale of the $y$ axis for the comparison to the upper benchmark (upper row; $\mathbf{a}$ and $\mathbf{b}$ ) and the lower benchmark (lower row; $\mathbf{c}$ and $\mathbf{d}$ ). Triangles indicate outliers that would plot outside the range of the $y$ axis.

The differences in the median improvement in the efficiency when using the data for five stream level classes compared to the lower benchmark $\left(L_{\text {random }}\right)$ between the wet, humid and dry catchments were also small $(0.23,0.32$ and 0.22 , respectively) but statistically significant (Kruskal-Wallis test $p=0.02$ ).

\subsection{Optimal location of class boundaries}

In order to determine the optimal location of the class boundaries, we systematically varied them for the cases with two and three stream level classes. The results show that model performance generally improved when at least one class boundary was located at high stream levels. For example, for the case with two classes, the median model performance for the 100 catchments was highest when the class boundary was chosen, so that the stream level was in the lower class for $94 \%$ of the time and in the upper class for $6 \%$ of the time. The smallest median difference between the model performance for two classes and the upper benchmark occurred at the class boundary definition of $93-7 \%$ (Fig. 5a). The variability in model performance also decreased when the boundary was chosen at a higher stream level, so that for fewer catchments the difference between the median model performance (i.e. the median performance of the 100 calibration parameter sets) and the upper benchmark was larger than $0.20\left(\Delta R_{\text {eff }}\right.$ was larger than 0.20 for $86,61,22$, and 

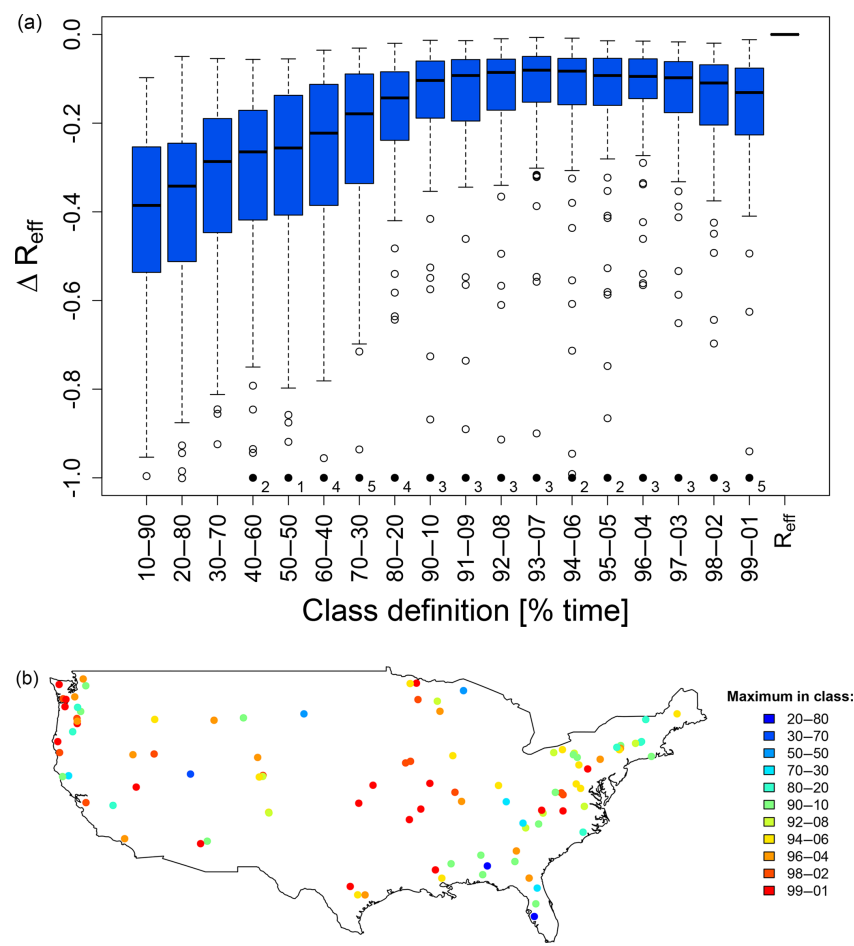

Figure 5. Difference in median model validation results relative to the upper benchmark ( $\left.\Delta R_{\text {eff }}\right)$ for models calibrated with two water level classes for different class boundary definitions (a) and a map of the optimal class boundary definition for each catchment (b). As an example, 20-80 indicates that streamflow was in the lower stream level class for $20 \%$ of the time and in the upper class for $80 \%$ of the time. The median difference in model efficiency and the upper benchmark is smallest when the class boundary is set at 93-7\%.

$22 \%$ of the catchments when the boundary was set at $10-90$, $50-50,90-10$, and $94-6 \%$ of the time, respectively). There was no clear spatial pattern in the optimal location of the class boundaries and for a few catchments the optimal class boundary was located at a much lower stream level (Fig. 5b). For the case with the three stream level classes, on average for the 100 catchments, better model results were obtained when the boundary for the upper class was at a high water level, but the other boundary could either be at a high level or at a low level (Fig. 6). Intermediate values for the lower boundary resulted in a poorer model performance. The median performance of the models calibrated with three water level classes for the 100 catchments was highest when the class boundaries were set, so that the water level was in the lowest, medium and highest classes 94,5 and $1 \%$ of the time, respectively.

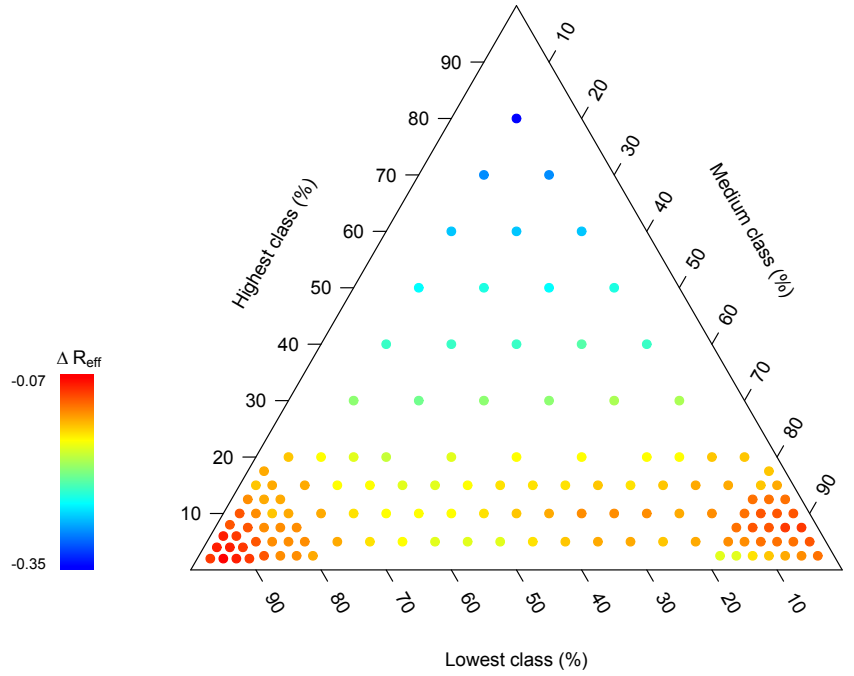

Figure 6. Median difference in model efficiency for models calibrated with data for three water level classes and the upper benchmark $\left(\Delta R_{\text {eff }}\right)$ for different class boundaries.

\section{Discussion}

\subsection{Usefulness of stream level class data}

The results of this study show that five stream level classes are as informative for model calibration as stream level data with a very high vertical resolution. This is good news for citizen science projects or webcam based analyses, as it is much easier to determine the stream level class when there are only a few classes than when there are many classes. The small difference between the performance of the models calibrated on data for a few stream level classes and the upper benchmark (Fig. 4a and b) suggests that the stream level class data from citizen science approaches or webcam images are most useful for model calibration for wet catchments and that stream level class data for these catchments can be used in combination with a model to obtain time series of streamflow. This is encouraging, as it is likely much harder for citizen scientists to estimate the streamflow than the stream level class, and this way the streamflow data that are needed for water management or flood or drought forecasting can be obtained from the stream level class data.

On the other hand, the large improvement of the models calibrated with stream level class data compared to the lower benchmark for some of the dry catchments (Fig. 4c and d) suggests that stream level class data may be especially useful in improving model performance in some dry catchments when no other streamflow or stream level data are available. For these catchments, the model performance of the lower benchmark (i.e. based on the random parameter sets) was very poor, while for the wet catchments the model performance of the lower benchmarks was already reasonably good (see the colour coding in Figs. 3 and 4). Thus the biggest gain 
in adding stream level class data was seen for some of the dry catchments, even though the absolute model performance was much poorer than for models calibrated on streamflow data. Seibert and Vis (2016) showed that model calibration based on high-resolution stream level data worked best for wet catchments, and that for dry catchments, additional data on the water balance were needed. Using such additional information may also improve model performance based on stream level class data for the dry catchments. What kind of additional information might be most useful in combination with stream level class data remains to be explored.

\subsection{Location of the class boundaries}

In practice, the boundaries between the different water level classes will be chosen based on features in the river or the stream bank that are easy to observe. The results from this study suggest that for most streams the optimal class boundaries should be located at the high flow levels, but not at the very highest flows. This high optimal class boundary is good news for model calibration based on opportunistic webcam images because high flows are usually easier to observe in these images than low flows because it may be difficult to see the water level at low flows when the camera does not focus directly on the stream. Citizen scientists, on the other hand, are perhaps more likely to go out and estimate stream levels during nice weather conditions and low flow periods. However, people also tend to look at rivers when the water level is particularly high. The still relatively long time that the water level is in the highest class (e.g. $6 \%$ of the time or on average 22 days per year for the case with two water level classes for which the median model performance for the 100 catchments was highest) suggests that there is ample time for citizen scientists to observe the water levels during the high water level period. These results thus suggest that citizen science projects should communicate to the participants that measurements during high water levels are important and worth collecting and transmitting.

The reasons that for the majority of the catchments the optimal boundary between the water level classes is located at high stream levels are related to the data, the model and the choice of the model evaluation criterion. The choice of a high water level class boundary helps to avoid the selection of a parameter set that leads to an overly flashy streamflow response because the water level is in the upper water level class for only a limited fraction of time. The information content of the water level class data, and thus its value for hydrological model calibration, is higher when we know that for some events the water level does not cross this boundary and for another set of events it does. If for every event the water level crosses the boundary because it is set at a low level, then it is not possible to distinguish between the responses of different events. Similarly, if the level is set too high, then the water level may cross the class boundary only a very few times so that no distinction can be made for the response of

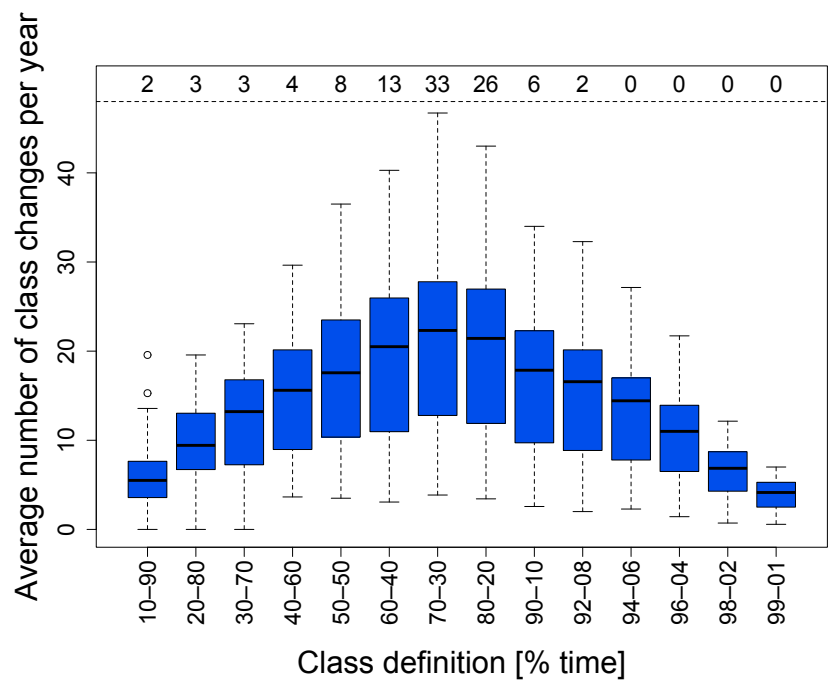

Figure 7. Box plots of the average number of times per year that the water level switched from one class to another for different class definitions. In the top row the number of catchments for which the number of water level class switches was highest at that class definition. As an example, 80-20 indicates that streamflow was in the lower stream level class for $80 \%$ of the time and in the upper stream level class for $20 \%$ of the time, and that for 26 of the 100 catchments this class boundary definition resulted in most class switches per year.

the majority of the events. For the optimal boundary definition for the two classes at $94-6 \%$ of the time, there were on average between 2.2 and 27.2 switches between the two water level classes per year (median: $14.4 ; 25$ th and 75 th percentiles: 8.0 and 17, respectively; Fig. 7). One could also argue that the water level class data are most informative when the class boundaries are crossed as often as possible in the actual time series. For the majority of the catchments the water level class boundary was most often crossed if it was set so that the water level was in the lower class for $60-80 \%$ of the time (Fig. 7). For only 8 of the 100 catchments was the water level class boundary most frequently crossed if it was set at such a level that it was in the lower class for less than $40 \%$ of the time; for 8 other catchments the water level class boundary was crossed most often if the boundary was defined such that the water level was in the lower class for more than $80 \%$ of the time (Fig. 7).

Wani et al. (2017) used censored data in a formal Bayesian framework to simulate the combined sewer overflow in an urban catchment. Similar to the results for the two water level classes here, they show that binary data (i.e. a water level above or below a threshold) are very effective in reducing the parameter uncertainty in their rainfall-runoff model. They show that the location of the threshold matters and highlight the high information content in crossing the threshold, but also mention that it is difficult to determine the relation between the location of the threshold and the value of the data 
in reducing the parameter space because it depends on how close the system is to the threshold and how many times the threshold is exceeded.

The optimal location of the water level class boundaries is also dependent on the model validation criterion that is used. We used the model efficiency $\left(R_{\text {eff }}\right.$, Nash and Sutcliffe, 1970) to evaluate model performance, which is known to give more weight to the evaluation of high flows (Krause et al., 2005; Schaefli and Gupta, 2007). A high water level class boundary provides more information for these high flows. Using a different model evaluation criterion that focuses less on the high flows would result in lower optimal class boundaries. For example, when using the log-transformed streamflow to evaluate the model performance, the model efficiency values (again median for the 100 catchments) were highest when the class boundary was chosen so that the stream water level was in the lower class for about $60 \%$ of the time when there are only two stream level classes, and the water level was in the lower, middle and upper classes for about 10,60 , and $30 \%$ of the time when there are three water level classes. In other words, the exact location of the optimal water level class boundaries depends on the model evaluation criteria and should be chosen based on the objective of the study (e.g. simulation of the peaks, low flow periods or the water balance).

Because in real citizen science projects the boundaries will not be chosen based on optimality as discussed above, but will be chosen by citizens based on local conditions, such as identifiable features in the stream, the usefulness of citizen science based water level class data for the simulation of different aspects of the hydrograph will differ. However, the investigation of theoretically optimal class boundaries is still valuable for at least two reasons. First, these results can be used to provide guidance to citizen scientists on how to choose class boundaries, if at all possible. Second, such results can help to decide which citizen science based water level class data might be especially useful for the simulation of a certain aspect of the hydrograph.

\subsection{Limitations of this study when faced with the reality of citizen science based data collection}

A challenge with citizen science based stream level data is that observations are taken at irregular time intervals, with a limited vertical resolution, and may contain errors. In this study, we addressed the issue of the limited vertical resolution by assessing the value of stream level class data. More work is needed on the issue of irregular data to determine the number of observations that are needed and the best times of these observations. Model calibration using weekly stream level class data for the cases with two, three and five water level classes suggests that the deterioration in model performance when weekly data are used instead of daily data is very small. Previous studies on model calibration based on streamflow measurements have also suggested that continuous streamflow data are not needed and that only a few streamflow measurements, particularly during rainfall events, are already useful for constraining hydrological models because many of the streamflow measurements contain redundant information (Seibert and Beven, 2009; RojasSerna et al., 2016).

In this study, we pretended to have stream level class data by transforming the streamflow data to stream level classes (Fig. 1). These data, therefore, do not include any errors. In reality, citizen science data may contain errors and misclassifications of the stream level. The effects of data errors on model results need to be tested as well. However, in this respect, it has to be mentioned that several studies have shown that citizen science data can be quite accurate (Cohn, 2008; Lowry and Fienen, 2013; Tye et al., 2017) (but not always, e.g. Savan et al., 2003) and that traditional streamflow data also can have significant uncertainties and may even contain dis-informative information that affects model calibration (McMillan et al., 2010; Beven and Westerberg, 2011).

\section{Conclusion}

This study demonstrates that stream level class data can be useful for calibrating hydrological models in otherwise ungauged catchments. The results confirm the conclusions from a previous study (Seibert and Vis, 2016), but more importantly extend the findings towards the use of stream level class data for model calibration to cases where data are available at only a limited vertical resolution, such as in citizen science based observation approaches or webcam image analysis. The results show that a small number of stream level classes contain almost as much information for hydrological model calibration as high-resolution water level data. This is good news for citizen science approaches. We also found that class boundaries at high water levels result in the most informative water level class time series. While in practice the class boundaries are likely determined by the local situation (such as a rock that is covered by water at a certain level), the importance of high levels shows the value of motivating the public to also collect data during high flow situations.

More generally, this study demonstrates how hydrological modelling can be used to evaluate the potential value of certain types of data. Similar approaches can be used to evaluate how much the information content of stream level class data might decrease if observations are made at irregular times or with a certain amount of error. This information is crucial for the optimal design and implementation of citizen science based observation approaches. 
Data availability. The streamflow data used in this study were obtained from Newman et al. (2015). The DAYMET precipitation data (Thornton et al., 2012) were obtained from the Newman et al. (2015) dataset as well. The HBV model software (Seibert and Vis, 2012) is available from the authors on request.

Competing interests. The authors declare that they have no conflict of interest.

Acknowledgements. We thank Andy Newman and Martyn Clark for making the data used in this study available. The ScienceCloud provided by S3IT at the University of Zurich enabled us to run the computationally intensive simulations on virtual machines. The comments of the two reviewers helped to clarify the text.

Edited by: Stefan Uhlenbrook

Reviewed by: Wouter Buytaert and Fernando Nardi

\section{References}

Bergström, S.: The HBV Model: Its Structure and Applications, Swedish Meteorological and Hydrological Institute, Swedish Meteorological and Hydrological Institute (SMHI) Hydrology, RH, No.4, Norrköping, 35 pp., 1992.

Beven, K. and Westerberg, I.: On red herrings and real herrings: disinformation and information in hydrological inference, Hydrol. Process., 25, 1676-1680, 2011.

Bonney, R., Cooper, C. B., Dickinson, J., Kelling, S., Phillips, T., Rosenberg, K. V., and Shirk, J.: Citizen science: a developing tool for expanding science knowledge and scientific literacy, Bioscience, 59, 977-984, 2009.

Cohn, J. P.: Citizen science: can volunteers do real research?, Bioscience, 58, 192-197, 2008.

Fohringer, J., Dransch, D., Kreibich, H., and Schröter, K.: Social media as an information source for rapid flood inundation mapping, Nat. Hazards Earth Syst. Sci., 15, 2725-2738, https://doi.org/10.5194/nhess-15-2725-2015, 2015.

Graham, E. A., Henderson, S., and Schloss, A.: Using mobile phones to engage citizen scientists in research, EOS T. Am. Geophys. Un., 92, 313-315, 2011.

Hilgersom, K. P. and Luxemburg, W. M. J.: Technical Note: How image processing facilitates the rising bubble technique for discharge measurement, Hydrol. Earth Syst. Sci., 16, 345-356, https://doi.org/10.5194/hess-16-345-2012, 2012.

Huddart, J. E. A., Thompson, M. S. A., Woodward, G., and Brooks, S. J.: Citizen science: from detecting pollution to evaluating ecological restoration, Wiley Interdisciplinary Reviews: Water, 3, 287-300, 2016.

Kirchner, J. W.: Getting the right answers for the right reasons: Linking measurements, analyses, and models to advance the science of hydrology, Water Resour. Res., 42, W03S04, https://doi.org/10.1029/2005WR004362, 2006.

Kundzewicz, Z. W.: Water resources for sustainable development, Hydrolog. Sci. J., 42, 467-480, 1997.
Krause, P., Boyle, D. P., and Bäse, F.: Comparison of different efficiency criteria for hydrological model assessment, Adv. Geosci., 5, 89-97, https://doi.org/10.5194/adgeo-5-89-2005, 2005.

Lindström, G., Johansson, B., Persson, M., Gardelin, M., and Bergström, S.: Development and test of the distributed HBV-96 hydrological model, J. Hydrol., 201, 272-288, 1997.

Little, K. E., Hayashi, M., and Liang, S.: Community-based groundwater monitoring network using a citizen-science approach, Groundwater, 54, 317-324, 2016.

Lowry, C. S. and Fienen, M. N.: CrowdHydrology: crowdsourcing hydrologic data and engaging citizen scientists, Groundwater, 51, 151-156, 2013.

McMillan, H., Freer, J., Pappenberger, F., Krueger, T., and Clark, M.: Impacts of uncertain river flow data on rainfall-runoff model calibration and discharge predictions, Hydrol. Process., 24, 1270-1284, 2010.

Milewski, A., Sultan, M., Yan, E., Becker, R., Abdeldayem, A., Soliman, F., and Gelil, K. A.: A remote sensing solution for estimating runoff and recharge in arid environments, J. Hydrol., 373, 1-14, 2009.

Mulligan, M.: WaterWorld: a self-parameterising, physically based model for application in data-poor but problem-rich environments globally, Hydrol. Res., 44, 748-769, 2013.

Muste, M., Ho, H. C., and Kim, D.: Considerations on direct stream flow measurements using video imagery: outlook and research needs, J. Hydro-Environ. Res., 5, 289-300, 2011.

Nash, J. E. and Sutcliffe, J. V.: River flow forecasting through conceptual models Part I - A discussion of principles, J. Hydrol., 10, 282-290, 1970.

Newman, A. J., Clark, M. P., Sampson, K., Wood, A., Hay, L. E., Bock, A., Viger, R. J., Blodgett, D., Brekke, L., Arnold, J. R., Hopson, T., and Duan, Q.: Development of a large-sample watershed-scale hydrometeorological data set for the contiguous USA: data set characteristics and assessment of regional variability in hydrologic model performance, Hydrol. Earth Syst. Sci., 19, 209-223, https://doi.org/10.5194/hess-19-209-2015, 2015.

Pavelsky, T. M.: Using width-based rating curves from spatially discontinuous satellite imagery to monitor river discharge, Hydrol. Process., 28, 3035-3040, 2014.

Rojas-Serna, C., Lebecherel, L., Perrin, C., Andréassian, V., and Oudin, L.: How should a rainfall-runoff model be parameterized in an almost ungauged catchment? A methodology tested on 609 catchments, Water Resour. Res., 52, 4765-4784, 2016.

Royem, A. A., Mui, C. K., Fuka, D. R., and Walter, M. T.: Technical note: Proposing a low-tech, affordable, accurate stream stage monitoring system, T. ASABE, 55, 2237-2242, 2012.

Savan, B., Morgan, J. A., and Gore, C.: Volunteer environmental monitoring and the role of the universities: the case of citizens' environment watch, Environ. Manage., 31, 0561-0568, 2003.

Schaefli, B. and Gupta, H. V.: Do Nash values have value?, Hydrol. Process., 21, 2075-2080, 2007.

Seibert, J.: Multi-criteria calibration of a conceptual runoff model using a genetic algorithm, Hydrol. Earth Syst. Sci., 4, 215-224, https://doi.org/10.5194/hess-4-215-2000, 2000.

Seibert, J. and Beven, K. J.: Gauging the ungauged basin: how many discharge measurements are needed?, Hydrol. Earth Syst. Sci., 13, 883-892, https://doi.org/10.5194/hess-13-883-2009, 2009.

Seibert, J. and Vis, M. J. P.: Teaching hydrological modeling with a user-friendly catchment-runoff-model software package, Hydrol. 
Earth Syst. Sci., 16, 3315-3325, https://doi.org/10.5194/hess-163315-2012, 2012.

Seibert, J. and Vis, M. J. P.: How informative are stream level observations in different geographic regions?, Hydrol. Process., 30, 2498-2508, 2016.

Smith, L. C.: Satellite remote sensing of river inundation area, stage, and discharge: a review, Hydrol. Process., 11, 1427-1439, 1997.

Spearman, C.: The proof and measurement of association between two things, Am. J. Psychol., 15, 72-101, 1904.

Stumpf, A., Augereau, E., Delacourt, C., and Bonnier, J.: Photogrammetric discharge monitoring of small tropical mountain rivers: a case study at Rivière des Pluies, Réunion Island, Water Resour. Res., 52, 4550-4570, 2016.

Thornton, P. E., Thornton, M. M., Mayer, B., Wilhelmi, N., Wei, Y., and Cook, R. B.: Daymet: Daily surface weather on a $1 \mathrm{~km}$ grid for North America, 1980-2012, available at: http://daymet. ornl.gov/ from Oak Ridge National Laboratory Distributed Active Archive Center, Oak Ridge, Tennessee, USA, 2012.

Tsubaki, R., Fujita, I., and Tsutsumi, S.: Measurement of the flood discharge of a small-sized river using an existing digital video recording system, J. Hydro-Environ. Res., 5, 313-321, 2011.
Turner, D. and Richter, H.: Wet/dry mapping: using citizen scientists to monitor the extent of perennial surface flow in dryland regions, Environ. Manage., 47, 497-505, 2011.

Tye, C. A., McCleery, R. A., Fletcher, R. J., Greene, D. U., and Butryn, R. S.: Evaluating citizen vs. professional data for modelling distributions of a rare squirrel, J. Appl. Ecol., 54, 628-637, https://doi.org/10.1111/1365-2664.12682, 2017.

Van Dijk, A. I. J. M., Brakenridge, G. R., Kettner, A. J., Beck, H. E., De Groeve, T., and Schellekens, J.: River gauging at global scale using optical and passive microwave remote sensing, Water Resour. Res., 52, 6404-6418, https://doi.org/10.1002/2015WR018545,

Wani, O., Scheidegger, A., Carbajal, J. P., Rieckermann, J., and Blumensaat, F.: Parameter estimation of hydrologic models using a likelihood function for censored and binary observations, Water Res., 121, 290-301, 2017.

Wiseman, N. D. and Bardsley, D. K.: Monitoring to learn, learning to monitor: a critical analysis of opportunities for indigenous community-based monitoring of environmental change in australian rangelands, Geogr. Res., 54, 52-71, 2016. 